\title{
Rapid Interphase and Metaphase Assessment of Specific Chromosomal Changes in Neuroectodermal Tumor Cells by in Situ Hybridization with Chemically Modified DNA Probes
}

\author{
T. CREMER,${ }^{* 1}$ D. TESIN, $*$ A. H. N. HOPMAN, ${ }^{\dagger}$ and L. MANUELIDIS* \\ * Section of Neuropathology, Yale University School of Medicine, New Itaven, Connecticut 06510, \\ and ${ }^{\dagger}$ Department of Pathology, University of Nijmegen, 6525 GA Nijmegen, The Netherlands
}

\begin{abstract}
Repeated DNAs from the constitutive heterochromatin of human chromosomes 1 and 18 were used as probes in nonradioactive in situ hybridization experiments to define specific numerical and structural chromosome aberrations in three human glioma cell lines and one neuroblastoma cell line. The number of spots detected in interphase nuclei of these tumor cell lines and in normal diploid nuclei correlated well with metaphase counts of chromosomes specifically labeled by in situ hybridization. Rapid and reliable assessments of aneuploid chromosome numbers in tumor lines in double hybridization experiments were achieved, and rare cells with bizarre phenotype and chromosome constitution could be evaluated in a given tumor cell population. Even with suboptimal or rare chromosome spreads specific chromosome aberrations were delineated. As more extensive probe sets become available this approach will become increasingly powerful for uncovering various genetic alterations and their progression in tumor cells. (C) 1988 Academic Press, Inc.
\end{abstract}

Specific chromosome aberrations are thought to be important in the development of malignant human gliomas. However, several groups have noted that adequate chromosome analyses of both primary cultures and of solid glioma samples are problematic $[1,2]$. These difficulties are generally encountered in all cytogenetic analyses of solid tumors; many tumor preparations do not contain sufficient numbers of well-spread and banded metaphase cells, and a large number of mitotic cells within solid tumors are inaccessible for analysis. With such small samples of mitotic cells it is difficult to determine if a chromosomal pattern is representative of the whole tumor cell population. Thus specific numerical and structural aberrations in a given tumor type are difficult to confirm on a broad scale, and rare aberrant cells with special malignant propensities may also be overlooked. Furthermore the analysis of complex chromosome changes in very aneuploid cells requires the detailed attention of highly skilled observers. Even when these time consuming analyses are performed by experienced cytogeneticists, it is difficult to pinpoint chromosomal breakpoints and segments involved in duplication, deletion, or translocation [1].

We are attempting to develop procedures and DNA probe sets for visualization of specific numerical and structural aberrations in tumor cells. The detection of chromosome abnormalities in interphase nuclei, an approach termed "interphase cytogenetics" [3], appears to be a useful addition to the classical metaphase analysis. The examination of numerical aberrations in interphase nuclei can yield

\footnotetext{
1 To whom reprint requests should be addressed.
} 
a first approximation of specific chromosomal aberrations in large populations of tumor cells. Rapid nonradioactive in situ hybridization procedures [4-13] including the simultaneous detection of two different nucleic acid sequences [11] may be readily applicable in laboratories attempting to quantitate aneuploidy of individual chromosomes in specific types of human malignancies. Although flow cytometry of hybridized nuclei $[14,15]$ can also be used in these analyses, microscopic examinations do not require sophisticated instrumentation and also yield reasonably reproducible data on aneuploidy. Furthermore, detailed interphase chromosome evaluations allow one to detect grossly abnormal cells which can make up an extremely minute proportion of the cell population. Detcction of structural rearrangements by the specific visualization of chromosomal subregions with chromosome-specific probes has already been reported in mitotic chromosomes [11, 16-19] and in interphase nuclei [20].

At the present time probe sets specific for individual chromosomes or large chromosomal regions are limited, but these limitations are likely to be overcome in the near future (cf. Discussion). Repeated DNAs often define large chromosomal domains and subsets of the centromeric alphoid repeat family [21-23] and other repetitive DNAs [24-26] are available and have been shown to hybridize preferentially to individual human chromosome regions, including those on chromosomes 1 [27-29], 15 [30], 18 [3, 31], X, and Y [20, 21, 28, 32, 33]. However, minor hybridization signals on additional chromosomes can be particularly problematic with the alphoid sequence variants (e.g. [3, 21]). Despite this limitation it has been possible to diagnose trisomy 21 [34] and trisomy 18 [3] in interphase nuclei of amniotic fluid cells.

In this study we labeled two recombinant plasmids pUC1.77 [24, 27-29] and L1.84 [3, 23, 31] to detect chromosome-specific repetitive sequences in the constitutive heterochromatin ( $C$-bands) of chromosomes 1 and 18 , respectively. We here refer to these plasmids as $1 \mathrm{c}$ and $18 \mathrm{c}$. The simultaneous detection of two probes that delineate different chromosomes provided an important internal control for the numerical assessment of both absolute and relative aneuploidy in our preparations. Labeling protocols included labeling with biotin [4, 5], amino acetylfluorene (AAF) [7], and mercury [9, 13, 35]. We chose three highly aneuploid cell lines derived from human malignant gliomas ([36] for review) for comparison with normal diploid cells and also evaluated a neuroblastoma cell line with near diploid chromosome numbers. We show that it is feasible under the conditions described below to detect apparently normal, deleted, and rearranged chromosomes 1 and 18 in metaphase spreads from these cell lines by in situ hybridization. Furthermore, we could reliably count their number in interphase nuclei using both single and double hybridization protocols, and have been able to show a trisomy 1 subpopulation that was difficult to assess quantitatively in rare mitotic cells of the neuroblastoma line.

\section{MATERIALS AND METHODS}

Cell types. Normal diploid human fibroblasts cultures $(46, \mathrm{XY})$ derived from newborn male foreskin were cultured as described [36] and studied at passages 7 to 13. Phytohemagglutinin-stimulated 

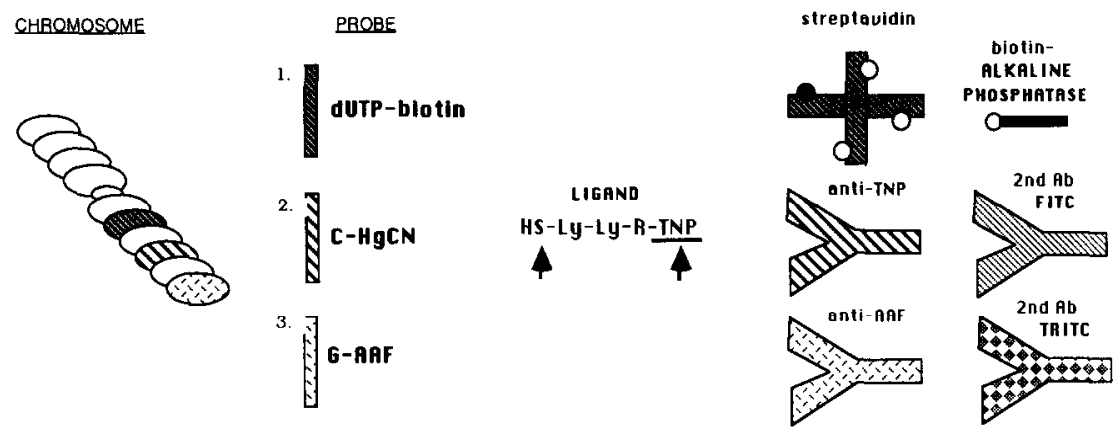

DENATURE AND HYBRIDIZE

DETECTION
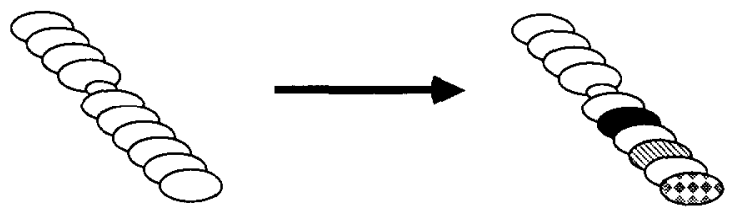

Fig. 1. In situ hybridization and detection scheme for DNA probes labeled with biotin, mercury, or aminoacetylfluorene (AAF). In the present experiments a biotinylated probe was combined with another probe labeled with either mercury or AAF (see Materials and Methods), although in principle three sequences can be detected simultaneously.

lymphocyte cultures from a normal adult male (46, XY) were grown in McCoy's $5 \mathrm{~A}$ medium for $72 \mathrm{~h}$ before harvesting. The cell lines TC 593 and TC 526 were originally established from two different human glioblastomas [36, 37]. TC 526 was chosen because it has particularly large numbers of aberrant chromosomes that are extremely difficult to analyze sufficiently by banding techniques according to experienced cytogeneticists (L. Manuelidis and R. Breg, unpublished data). TC 620 was derived from a human oligodendroglioma [36]. In the present experiments we utilized subclones $C 2 \mathrm{D}$ (TC 526), C2B (TC 593), and C2B (TC 620) at approximately 150 passages after repeated subcloning from a single cell of the original tumor line. The neuroblastoma line TC 691 was selected by repeatedly picking cells with a neuronal phenotype in early cultures of a phenotypically mixed tumor cell population [36]. Standard hypotonic treatment of cells and fixation were employed. Briefly, $0.075 M$ $\mathrm{KCl}$ or $10 \%$ fetal calf serum in distilled water was used to swell cells for 10 to $25 \mathrm{~min}$ at $22^{\circ} \mathrm{C}$, and cells were fixed with several changes of acetic acid/methanol $(1: 3, \mathrm{v} / \mathrm{v})$, prior to spreading on clean moist slides. Air-dried slides were washed after fixation twice with PBS (140 $\mathrm{m} M \mathrm{NaCl}, 10 \mathrm{mM} \mathrm{Na}$ phosphate, $\mathrm{pH} 7.0$ ), dehydrated with an ethanol series $(70,90,100 \%, 5 \mathrm{~min}$ each), and stored in sealed boxes at $4^{\circ} \mathrm{C}$.

DNA probes. The 1c probe (pUC1.77) represents a $1.77-\mathrm{kb}$ EcoRI fragment of human satellite III DNA [24] cloned in pUC9. The $18 \mathrm{c}$ probe (L1.84) contains a 684-bp long EcoRI fragment of human alphoid DNA cloned in pAT153 [23]. The cloned probes were generous gifts of Howard Cooke (pUC1.77) and Peter Devilee and Peter Pearson (L1.84). DNA plasmid preparations were purified as described [38] for labeling with bio-11-dUTP (BRL) to yield a final probe length of 200 to 400 nucleotides [39]. Modifications of DNA with AAF [7] or with mercury [9, 13] were done essentially as described in those publications. After AAF modification or mercuration, labeled DNAs were sonicated in TE buffer to yield 200 - to 400 -bp fragments as analyzed by agarose gel electrophoresis.

In situ hybridization. Optimal hybridizations were done in $60 \%$ formamide-2x SSC with $2-4 \mu \mathrm{g} / \mathrm{ml}$ of labeled probe. When using mercurated DNA probes, $5 \mathrm{mM} \mathrm{KCN}$ and $2 \times \mathrm{SSC}$ at pH 5.0 (yielding a final $\mathrm{pH}$ at approx $\mathrm{pH} 7$ ) were used in the hybridization mixtures. Cyanide ions neutralize the positive charge of the mercury ions and are a prerequisite for an efficient hybridization of mercurated nucleic acid probes [9]. Labeled probes were used individually or in combinations of two, i.e., either a biotinylated probe together with an AAF-modified probe, or a biotinylated probe together with a mercurated probe. The overall strategy is depicted in Fig. 1. In our hands cohybridization of 
mercurated probes with AAF-labeled probes resulted in nonspecific signals on metaphase chromosomes and interphase nuclei and thus triple hybridizations were not feasible with our standard protocols. Successful triple hybridizations using biotinylated, mercurated, and AAF-modified probes have been carried out, however, recently by another group (M. van der Ploeg, personal communication). The hybridization mixture was added to dry slides $\left(2.5 \mu \mathrm{l} / \mathrm{cm}^{2}\right)$, a coverglass was sealed with rubher cement, and denaturation of probe and cellular DNA was carried out by heating the slides to $86^{\circ} \mathrm{C}$ for 8 to $11 \mathrm{~min}$ in an oven [6]. Preparations were hybridized for 14 to $20 \mathrm{~h}$ at $37^{\circ} \mathrm{C}$ in a moist chamber. After hybridization, slides were washed with $50 \%$ formamide- $2 \times \mathrm{SSC}$ with $1 \mathrm{mM} \mathrm{KCN}$, pH 7 (two times for $15 \mathrm{~min}$ at $22^{\circ} \mathrm{C}$ and once for $30 \mathrm{~min}$ at $42^{\circ} \mathrm{C}$ ) followed by washes with $2 \times \mathrm{SSC}, 1$ $\mathrm{m} M \mathrm{KCN}$ at $22^{\circ} \mathrm{C}$ (KCN was omitted if mercurated probes were not used, i.e., for biotin and AAFlabeled DNAs). While KCN is essential for hybridization with mercurated probes (see above) it did not interfere adversely in double hybridization experiments with biotinylated probes. It should be noted that the stringency of hybridization and posthybridization washes is crucial for detection of "chromosome specific" labeling by 1c and 18c DNA probes. These DNA inserts will hybridize to several chromosomes in addition to chromosomes 1 and 18 with reduced formamide concentrations, e.g., at $40 \%$ formamide [3, 27, 31]. Hybridization mixtures with formamide concentrations higher than $60 \%$, or posthybridization washes at higher temperatures, yielded weaker but not significantly more specific signals.

Detection of hybridized probes. A protocol for the bicolor fluorescence detection of mercurated and biotinylated probes has been described previously [11]. We here describe the combination of fluorescence detection with the detection of enzymatically produced colored precipitates for the combination of biotinylated probes with either mercurated or AAF-labeled probes. All detection reagents were made in PBS- $0.1 \%$ Tween 20 with $1 \%$ BSA or $2 \%$ normal serum (from species of secondary antibody detectors) and washes between steps were three times for $5 \mathrm{~min}$ in PBS- $0.1 \%$ Tween.

In double hybridization experiments with biotinylated and mercurated probes the slides were first incubated at $37^{\circ} \mathrm{C}$ in the dark for $40 \mathrm{~min}$ with reduced mercury binding sulfhydryl-trinitrophenyl ligand (TNP-Lys-Lys-NH-CH$-\mathrm{CH}_{2}-\mathrm{SH}$ ) in PBS as described previously [12]. Thereafter the slides were incubated with a combination of sheep anti-TNP serum $(1: 200$, Netherlands Red Cross Blood Transfusion Service) and streptavidin $(2 \mu \mathrm{g} / \mathrm{ml})$ for $45 \mathrm{~min}$ at $37^{\circ} \mathrm{C}$. After washing, slides were exposed to FITC-conjugated rabbit anti-sheep antibody $(1: 80$, Dacopatts) and $2 \mu \mathrm{g} / \mathrm{ml}$ biotinylated alkaline phosphatase (AP). The alkaline phosphatase reaction was carried out at $\mathrm{pH} 9.5$ according to suppliers directions (BRL) for $30 \mathrm{~min}$ to $1 \mathrm{~h}$ at $37^{\circ} \mathrm{C}$ [40]. Preparations were then counterstained with DAPI

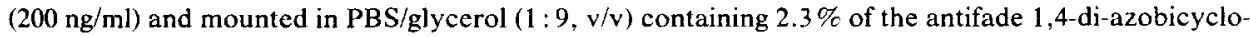
$(2,2,2)$-octane (Sigma) [13].

In double hybridization experiments with biotinylated and AAF-modified probes, detection included streptavidin $(2 \mu \mathrm{g} / \mathrm{ml})$ combined with mouse monoclonal antibodies against AAF ( $1: 250$, gift of $R$. A. Baan) in the first incubation. The second step included biotinylated alkaline phosphatase as above combined with goat anti-mouse IgG labeled with FITC or TRITC (1:100, Sigma). In some cases rabbit anti-AAF ( $1: 500$; also a gift of R. A. Baan) and goat anti-rabbit IgG conjugated with alkaline phosphatase $(1: 1000$, Tago) were applied for detection of AAF-modified probes, while avidin-TRITC (1:1000, Vector) was used to detect biotinylated probes. Microphotographs were taken with an inverted Nikon microscope, equipped for FITC, TRITC, and DAPI fluorescence, using Kodak ectochrome 400 color slide film. For double exposures (FITC/DAPI or TRITC/DAPI) a small amount of transmitted light was occasionally used to improve the photographic signal of the alkaline phosphatase reaction in DAPI-stained nuclei.

\section{RESULTS}

Diploid human lymphocyte cultures and early passage diploid fibroblast cultures $(46, X Y)$ were used to test the fidelity of our hybridization and interphase chromosome counts using probes $1 \mathrm{c}$ and $18 \mathrm{c}$. Figurcs $2 a$ and $3 a$ show examples of metaphase plates from human diploid cells indicating specific labeling of two chromosomes 1 with 1c (Fig. $2 a$ ) and two chromosomes 18 with 18c (Fig. $3 a$ ). Under the stringency conditions described under Materials and Methods major signals were confined to the C-band region 1q12 of chromosome 1 and the pericentric region of chromosome 18 . Occasional minor signals over the centro- 

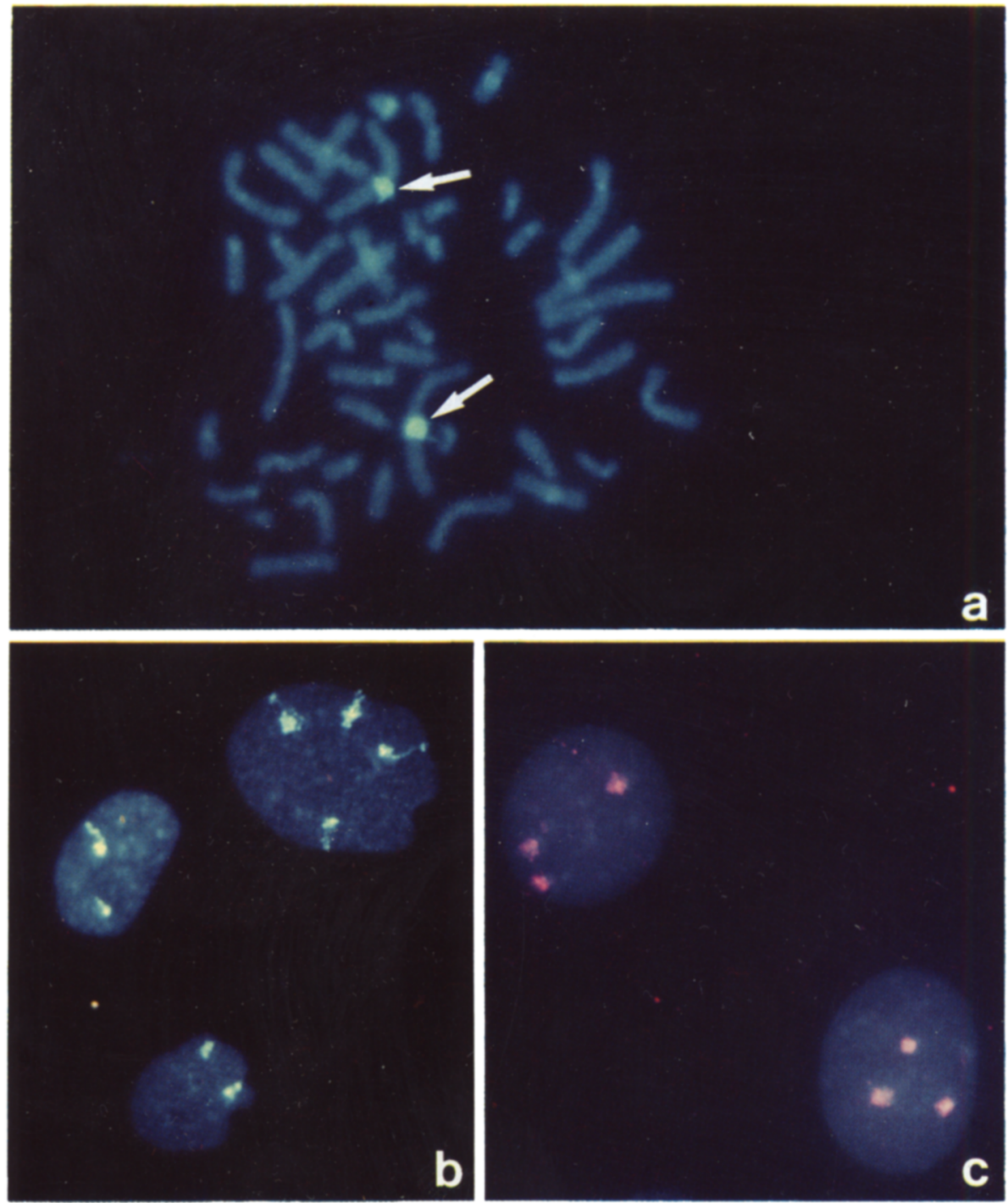

Fig. 2. (a) Metaphase spread from a human fibroblast culture (46, XY) after in situ hybridization with mercury-labeled $1 \mathrm{c}$ and FITC detection. Arrows indicate specific FITC fluorescence at position 1q12 (C-band) of both chromosomes 1. Chromosomes are counterstained with DAPI; double exposure; $\times 1590$. (b) Three fibroblast nuclei from the same preparation. Two smaller nuclei (right) each show two distinct green-whitish spots indicating the C-band positions of chromosome 1 within these nuclei. The 4-spot nucleus represents a rare tetraploid cell; double exposure; $\times 870$. (c) Two nuclei from the human oligodendroglioma cell line TC 620 after in situ hybridization with biotinylated 1c and avidin/TRITC detection. Note three well-separated pink-colored spots in each nucleus (see metaphase shown in Fig. $7 a$ ). Nuclei counterstained with DAPI; double exposure; $\times 1320$. FITC and TRITC spots appear distinctly green and red, respectively, when viewed with the appropriate filter sets. The change in color is due to double exposure with DAPI fluorescence. 

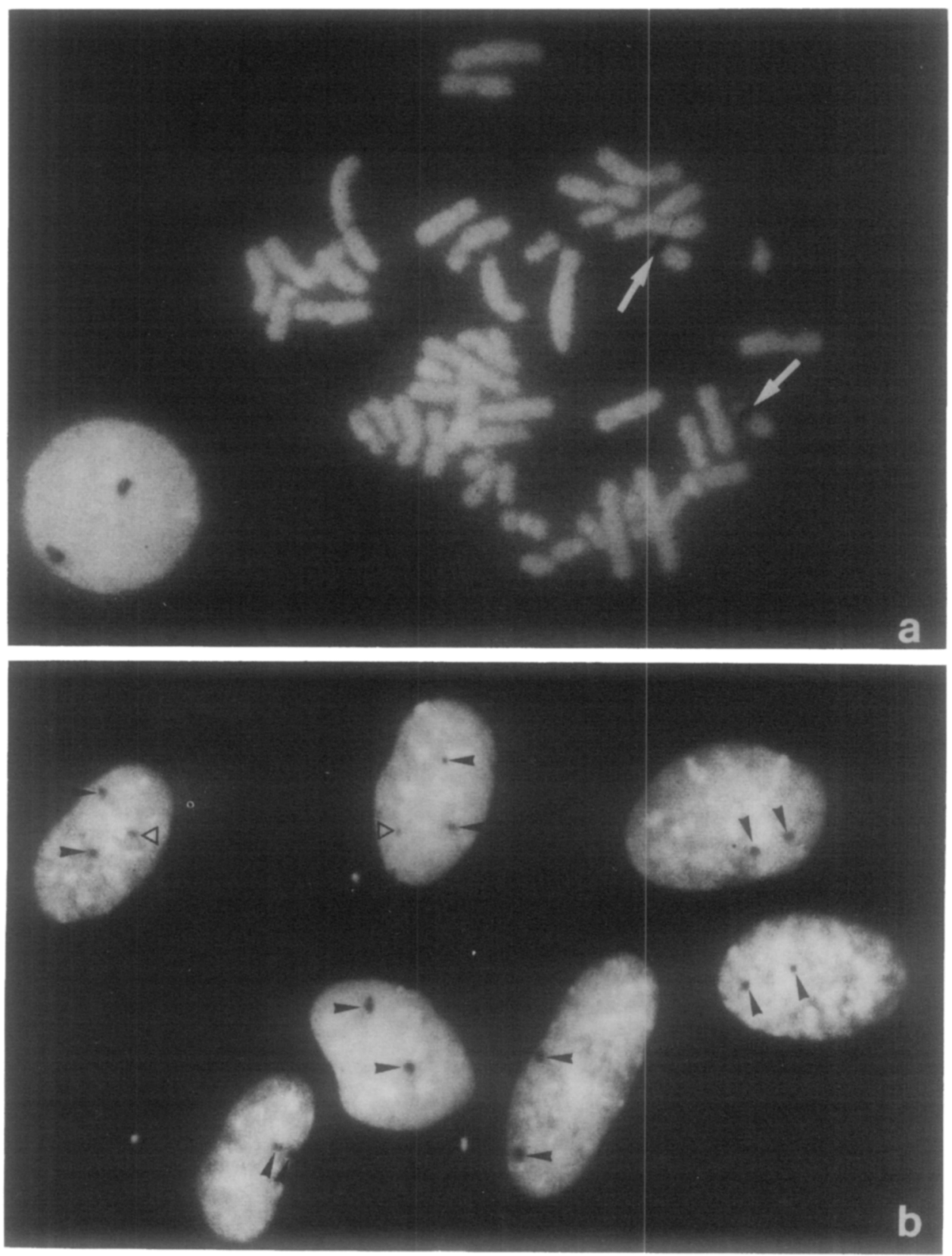

Fig. 3. (a) Metaphase spread from PHA-stimulated human lymphocyte culture after in situ hybridization with biotinylated $18 \mathrm{c}$, alkaline phosphatase detection, and DAPI staining. Arrows point to specific label at the centromeric regions of both chromosomes 18 . An adjacent interphase nucleus also shows two distinct separate labeled sites; $\times 2185$. (b) Typical nuclei from a human diploid fibroblast culture after in situ hybridization with $18 \mathrm{c}$ and detection with alkaline phosphatase. The two 18 specific spots (arrowheads) are largely separated in most nuclei. In one of these nuclei (which are rather flat in the third dimension) arrowheads show a close approximation of two spots. Two nuclei show a third (minor) hybridization site (open triangle); $\times 1460$. 
TABLE 1

Normal cells-Frequencies of hybridization spots detected in interphase nuclei of diploid human fibroblast and lymphocyte cultures $(46, X Y)$ after in situ hybridization with DNA probes $1 \mathrm{c}$ or $18 \mathrm{c}$ : Comparison of different probe labeling and detection protocols

\begin{tabular}{|c|c|c|c|c|c|c|c|c|c|}
\hline \multirow[b]{2}{*}{ Cell type } & \multirow[b]{2}{*}{ Experiment } & \multirow{2}{*}{$\begin{array}{l}\text { DNA } \\
\text { probe }\end{array}$} & \multirow{2}{*}{$\begin{array}{c}\text { Probe-label/ } \\
\text { detector }\end{array}$} & \multirow[b]{2}{*}{$n$} & \multicolumn{5}{|c|}{ Percentage of nuclei with spot number } \\
\hline & & & & & 0 & 1 & 2 & 3 & $\geqslant 4$ \\
\hline \multirow[t]{4}{*}{ Fibroblasts } & I. 1 & $1 \mathrm{c}$ & AAF/TRITC & 232 & 7.8 & 16.4 & 73.7 & 1.7 & 0.4 \\
\hline & 1.2 & $1 \mathrm{c}$ & AAF/FITC & 133 & 10.5 & 24.8 & 61.8 & 1.5 & 1.5 \\
\hline & 1.3 & $1 \mathrm{c}$ & AAF/AP & 120 & 9.2 & 14.2 & $\mathbf{7 5 . 0}$ & 0.8 & 0.8 \\
\hline & $\mathrm{I} .4$ & 1c & $\mathrm{Hg} / \mathrm{FITC}$ & 150 & 20.0 & 33.3 & 45.3 & 0.7 & 0.7 \\
\hline \multirow[t]{3}{*}{ Lymphocytes } & I.5 & $1 \mathrm{c}$ & $\mathrm{Hg} / \mathrm{FITC}$ & 200 & 0.0 & 14.0 & 85.0 & 0.0 & 1.0 \\
\hline & I. 1-5 & lc & All above & 835 & 9.5 & 20.5 & 68.2 & 0.9 & 0.9 \\
\hline & $($ mean $\pm S E M)$ & & & & \pm 3.2 & \pm 3.7 & \pm 6.8 & \pm 0.3 & \pm 0.2 \\
\hline Fibroblasts/ & I. $6-11$ & $18 \mathrm{c}$ & Biotin/AP & 818 & 8.8 & 14.5 & 64.6 & 6.9 & 5.2 \\
\hline lymphocytes & $($ mean $\pm S E M)$ & & & & \pm 1.8 & \pm 1.7 & \pm 1.9 & \pm 2.0 & \pm 1.2 \\
\hline
\end{tabular}

Note. $n$, number of nuclei; SEM, standard error of the mean. The peak fraction is indicated in bold face type.

meric regions of other chromosomes such as chromosome 9 in case of 1c and chromosome 2 in case of $18 \mathrm{c}$ indicated some cross-hybridization to related sequences in the constitutive heterochromatin of these other chromosomes [3, $27,31]$. Generally these minor signals were easily distinguished on the basis of intensity.

In interphase the majority of these diploid nuclei should reveal two major hybridization signals (for each probe) provided that homologous chromosomes are clearly separated; additionally, a few nuclei might show four spots due to occasionally observed polyploidization events. Indeed these predictions were borne out by in situ hybridization experiments. Table 1 shows a comparison of different probe labeling and detection protocols used for in situ hybridization with normal diploid cells. Essentially equivalent results were obtained in each case. Interphase nuclei were classified as 0-spot, 1-spot, 2-spot nucleus, etc., according to the number of major hybridization signals detected. We consistently found that a majority of normal diploid interphase nuclei showed two spots after in situ hybridization with either $1 \mathrm{c}$ or $18 \mathrm{c}$ (Table 1 , Figs. $2 b, 3 b, 4 a$ ). In order not to bias our counts, additional minor signals were included where they could not be obviously distinguished from major signals. Otherwise, clearly minor signals were excluded from further consideration. In experiments with $1 \mathrm{c}$ approximately $2 \%$ of the nuclei showed more than two spots. In experiments with $18 \mathrm{c}$ this percentage was significantly higher $(12 \%)$.

To evaluate the reliability of detection which may be impaired by occasional poor penetration of probe, incomplete denaturation of target DNA, and/or DNA losses in some nuclei, we counted the number of diploid nuclei with no or only one spot. These estimates were important for assessing our potential error in counting chromosome numbers in unknown samples. Notably percentages observed for 1 -spot and 0 -spot nuclei varied and were preparation dependent, i.e., 
older preparations yielded more incomplete hybridizations. Experiment I.4 in Table 1 shows one such poor preparation where only $45.3 \%$ of the nuclei showed the expected 2-spot number. However, even in this technically poor preparation the predicted diploid peak was obvious. Experiments I.6-11 in Table 1 demonstrate the reproducibility of interphase counts of chromosome 18 using biotinylated $18 \mathrm{c}$ together with the alkaline phosphatase detection protocol in selected fibroblast and lymphocyte preparations of reasonable quality. Thus the standard error of the mean (SEM) is considerably smaller than in the experiments shown in I. 1-5 (Table 1).

Based on this evidence we extended our investigation to three cell lines derived from human gliomas. These cell lines were chosen because they exhibit clearly different modal chromosome numbers. The peak values of the chromosome profiles were 64 for line TC 620, 83 for line TC 593, and 155 for line TC 526 [36]. TC 526 has a very broad numerical chromosome profile indicating extreme aneuploidy [36]. These different chromosome profiles let us expect that the numbers of normal and/or aberrant chromosomes detectable by in situ hybridization experiments with $1 \mathrm{c}$ and $18 \mathrm{c}$ should also be increased to a different extent. This expectation was confirmed. After in situ hybridization with either $1 \mathrm{c}$ or $18 \mathrm{c}$ the majority of TC 620 nuclei ("peak fraction") showed three spots for each probe, while the peak fraction of TC 593 nuclei showed four spots (Table 2; Figs. $2 c, 5,8 c)$. Identical peak fractions of $1 \mathrm{c}$ and $18 \mathrm{c}$ spots in TC 620 and TC 593, respectively, suggest polyploidization in each tumor cell population, although over- or underrepresentation of chromosomes other than 1 and 18 cannot be definitely addressed by the present experiments. However, restriction enzyme alphoid DNA bands are comparablc [61] suggesting a relatively even representation of most chromosomes. Histograms of counts of $1 \mathrm{c}$ and/or $18 \mathrm{c}$ spots in interphase nuclei of these three tumor lines as compared to normal cells are shown in Figs. $4 a-d$. Double hybridization experiments revealed for both TC 620 and 593 that an increase in spot number obtained in individual nuclei with one probe was generally accompanied by a similar increase in spot number obtained with the accompanying probe (Fig. 5). Notably, examination of individual nuclei showed that the relative spot numbers of the two probes could vary substantially (Fig. 6). The variability of spots counted in individual nuclei was most pro-

Fig. 4. Frequency distribution of the number of hybridization spots obtained after in situ hybridization with $1 \mathrm{c}$ (white columns) and $18 \mathrm{c}$ (hatched columns) in (a) normal diploid fibroblasts TC 714 and three human glioma cell lines TC $620(b, f)$, TC $593(c, g)$, and TC $526(g, h)$. The abscissa plots the number of hybridization spots. The ordinate shows the percentage of cells with a given number of hybridization spots in interphase nuclei $(a-d)$ and corresponding metaphase cells $(f-h)$. Each percentage was calculated from a total of 50 metaphase spreads and $>300$ to 700 interphase nuclei, and includes several preparations with different probe-label/detector combinations (see Tables 1 and 2). In general, a close agreement is noted between the numbers of $1 \mathrm{c}$ spots and $18 \mathrm{c}$ spots in interphase nuclei and metaphase spreads from each cell line. The last number on the abscissa for TC 620,593 , and 526 includes $\geqslant$ to the number indicated. In $(e)$ combined data for interphase nuclei and metaphase spreads are depicted. Note clearly distinct peak fractions for each cell line. Each point represents the average of spot numbers with equal weight given to the interphase and metaphase averages. For TC 526 values were scaled up by a factor of 2 . The curve for normal diploid cells (nl) combines all data for human fibroblasts and lymphocytes (see Table 1). 
Chromosome aberration assessment 207
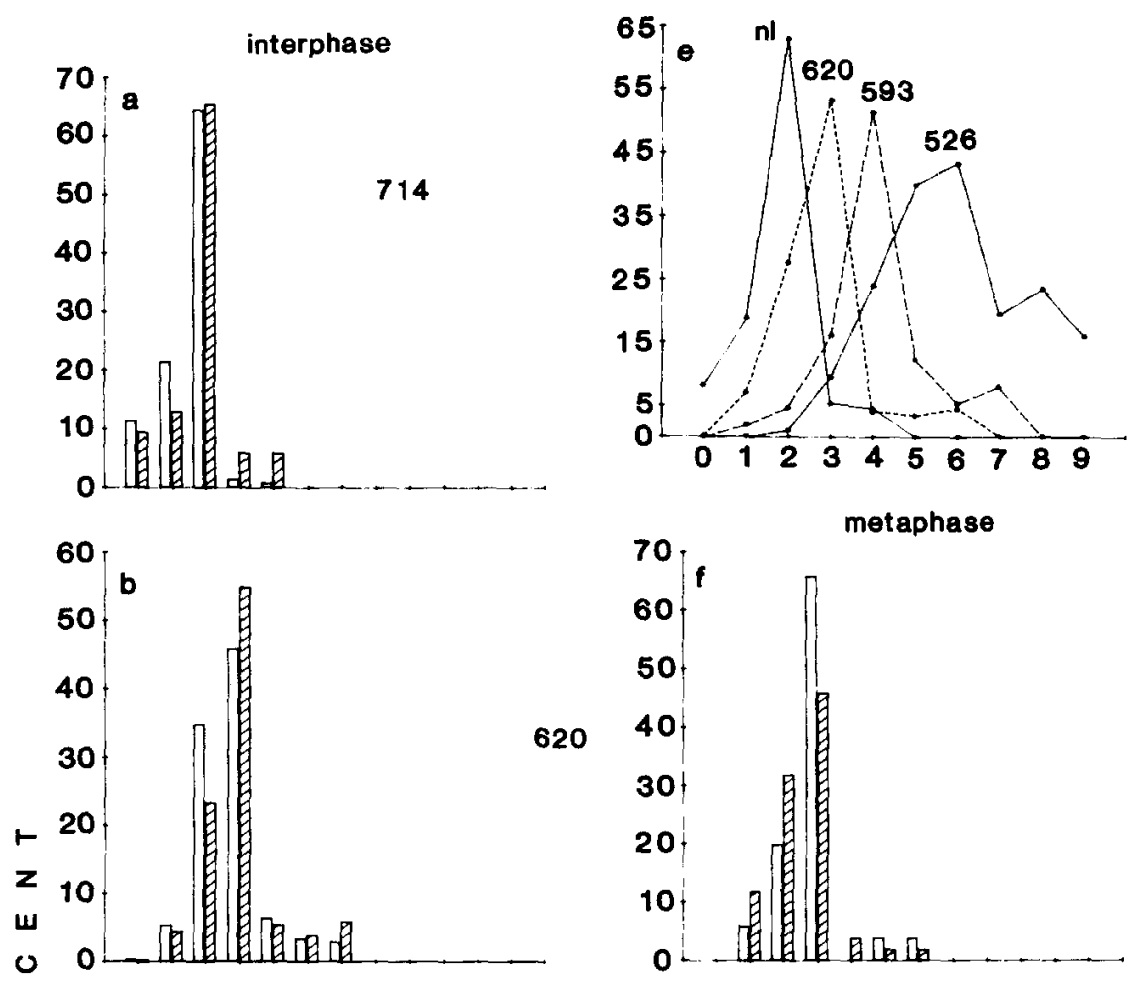

× 65
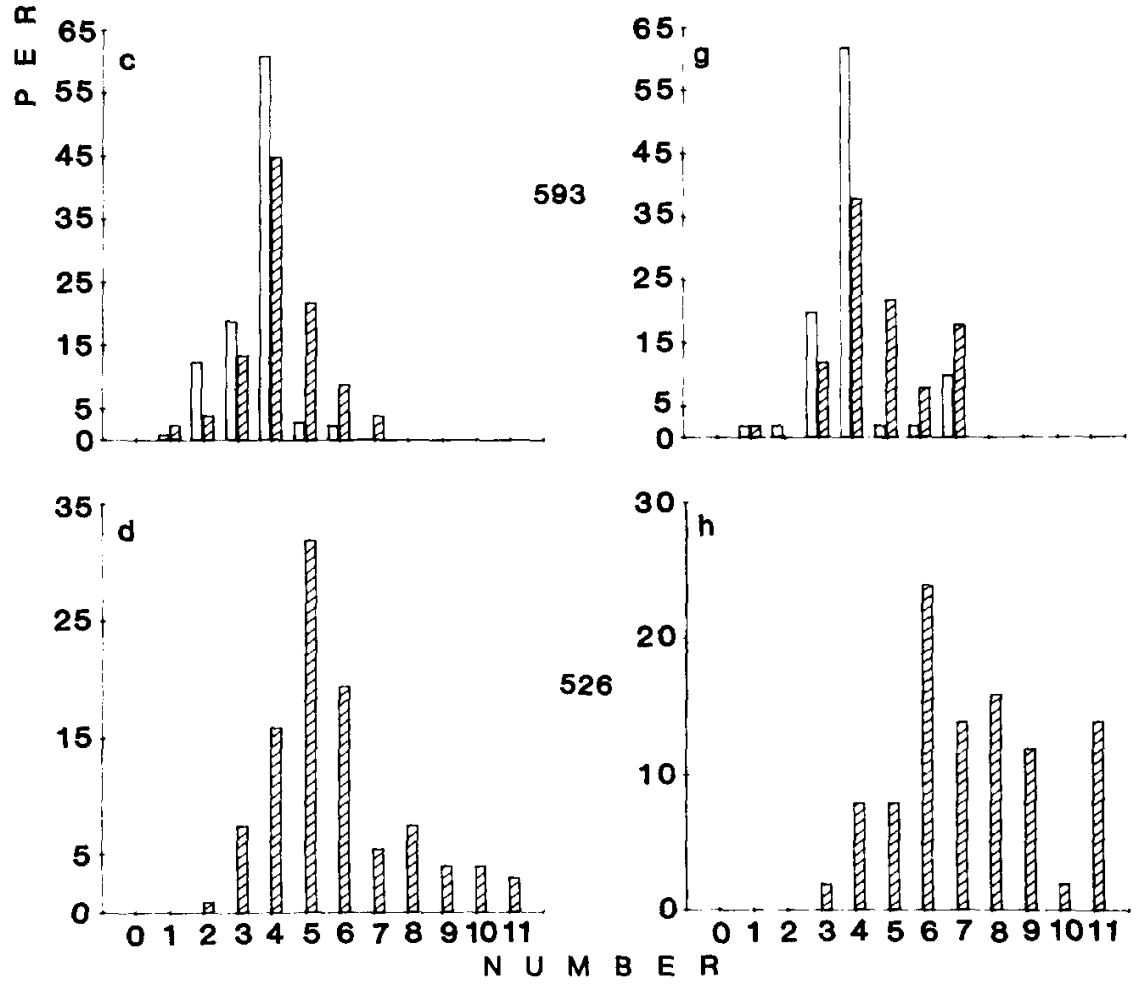

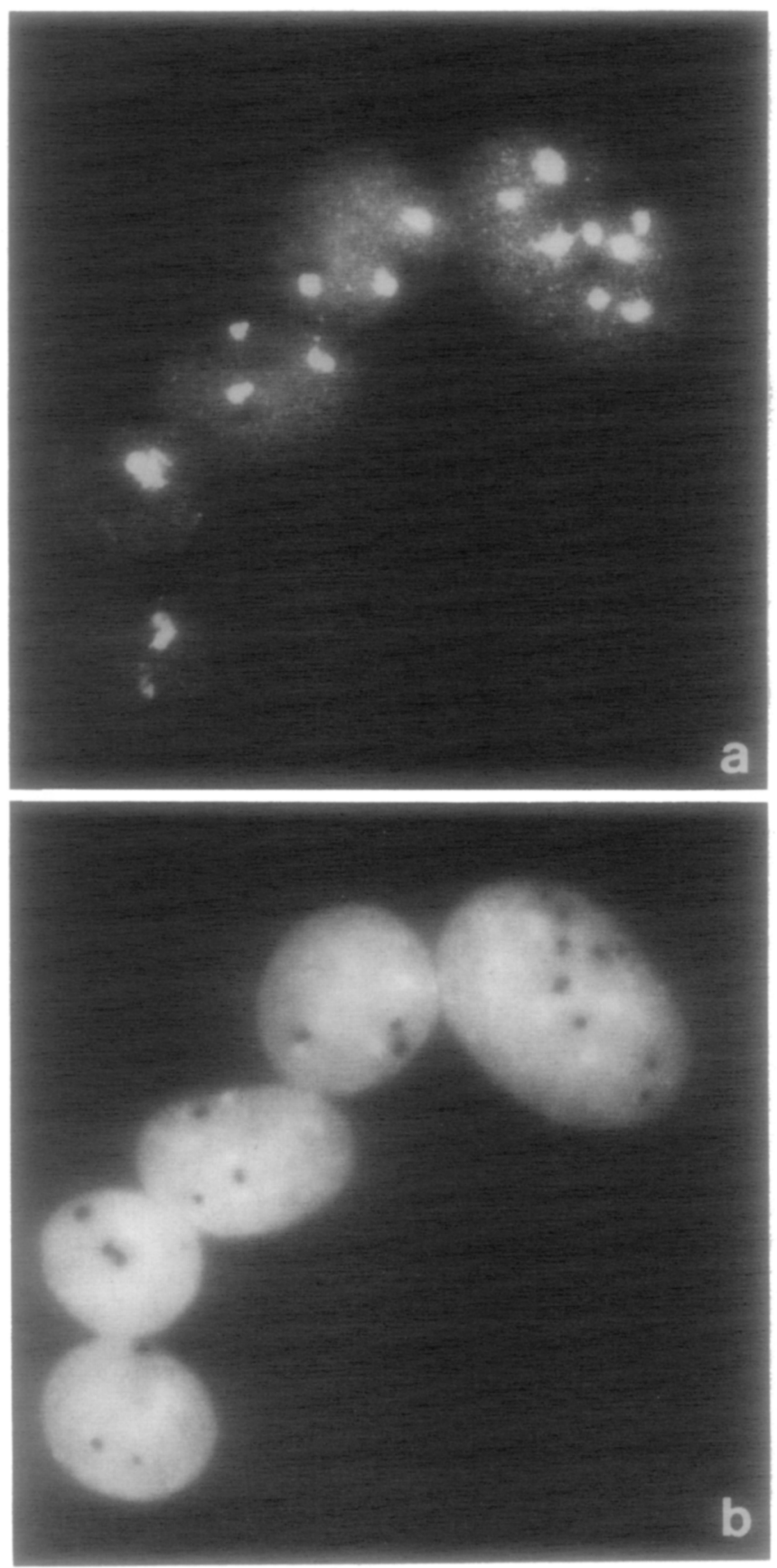

Fig. 5. Oligodendroglioma cell line TC 620 after double hybridization with (a) 1c (AAF/FITC detection) and $(b)$ 18c (biotin/alkaline phosphatase detection). Fluorescence microphotographs of FITC $(a)$ and alkaline phosphatase detection combined with DAPI $(b)$ in corresponding nuclei. Note general correspondence between numbers of each chromosome detected. There is no obvious association of $1 \mathrm{c}$ and $18 \mathrm{c}$ spots; $\times 1540$. 


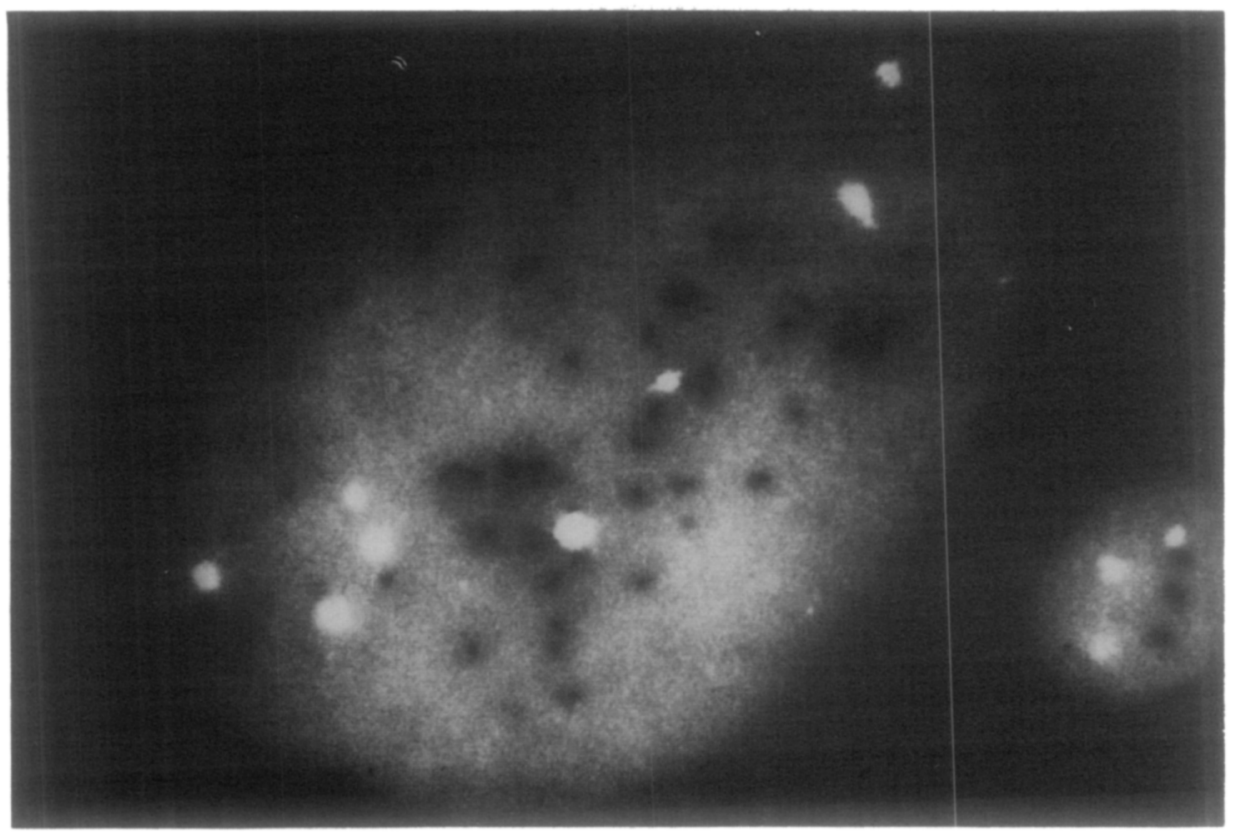

Fig. 6. Rare giant nuclcus from human oligodendroglioma line TC 620 after double hybridization with 1c (AAF/FITC) and 18c (biotin/alkaline phosphatase) showing numerous $1 \mathrm{c}$ and $18 \mathrm{c}$ hybridization sites with a relative excess of $18 \mathrm{c}$ sites. For comparison note the normal-sized nucleus (right) showing three ic and three $18 \mathrm{c}$ sites. Note also a close pairwise association of several $18 \mathrm{c}$ spots but not of the 1c spots in this unusual cell; $\times 1460$.

nounced for TC 526 with a peak number of five to six $18 \mathrm{c}$ spots. Using the 1c probe the number of chromosome spots in TC 526 nuclei were difficult to count due to a pronounced variability in signal intensity. Most nuclei $(\sim 80 \%)$ showed between two and six larger and more intense spots and a variable number of additional smaller, less intense spots (Figs. $9 a, b$ ).

Interphase chromosome counts in glioma cells were confirmed in analyses of metaphase plates (Figs. $4 f-h$ ). A close agreement of the peak fractions was noted between the numbers of $1 \mathrm{c}$ and $18 \mathrm{c}$ spots in interphase nuclei and metaphase spreads from each cell line. The differences between the histograms for the different cell types as shown in Fig. 4 are highly significant $(P<0.001)$ by the Mann-Whitney $U$ test [60]. A relative excess of TC 526 metaphase spreads over interphase nuclei with higher numbers of $18 \mathrm{c}$ spots (Figs. $4 d, h$ ) was likely due to technical reasons, since hybridization spots were more easily identified and counted in these metaphase spreads. Figures 7 and 8 show metaphase spreads from TC 620 and TC 593 after double hybridization with 1c and 18c. Note three major hybridization signals for both $1 \mathrm{c}$ and $18 \mathrm{c}$ in a metaphase spread of TC 620 and five signals in a metaphase plate of TC 593.

We were also able to detect chromosome deletions and rearrangements in these glioma preparations. No gross alterations were obvious in the three DAPI-stained chromosomes 1 of cell line TC 620 (Fig. 7 b). In contrast, the short arm of at least one chromosome 1 was largely missing (due to deletion or translocation) in all 

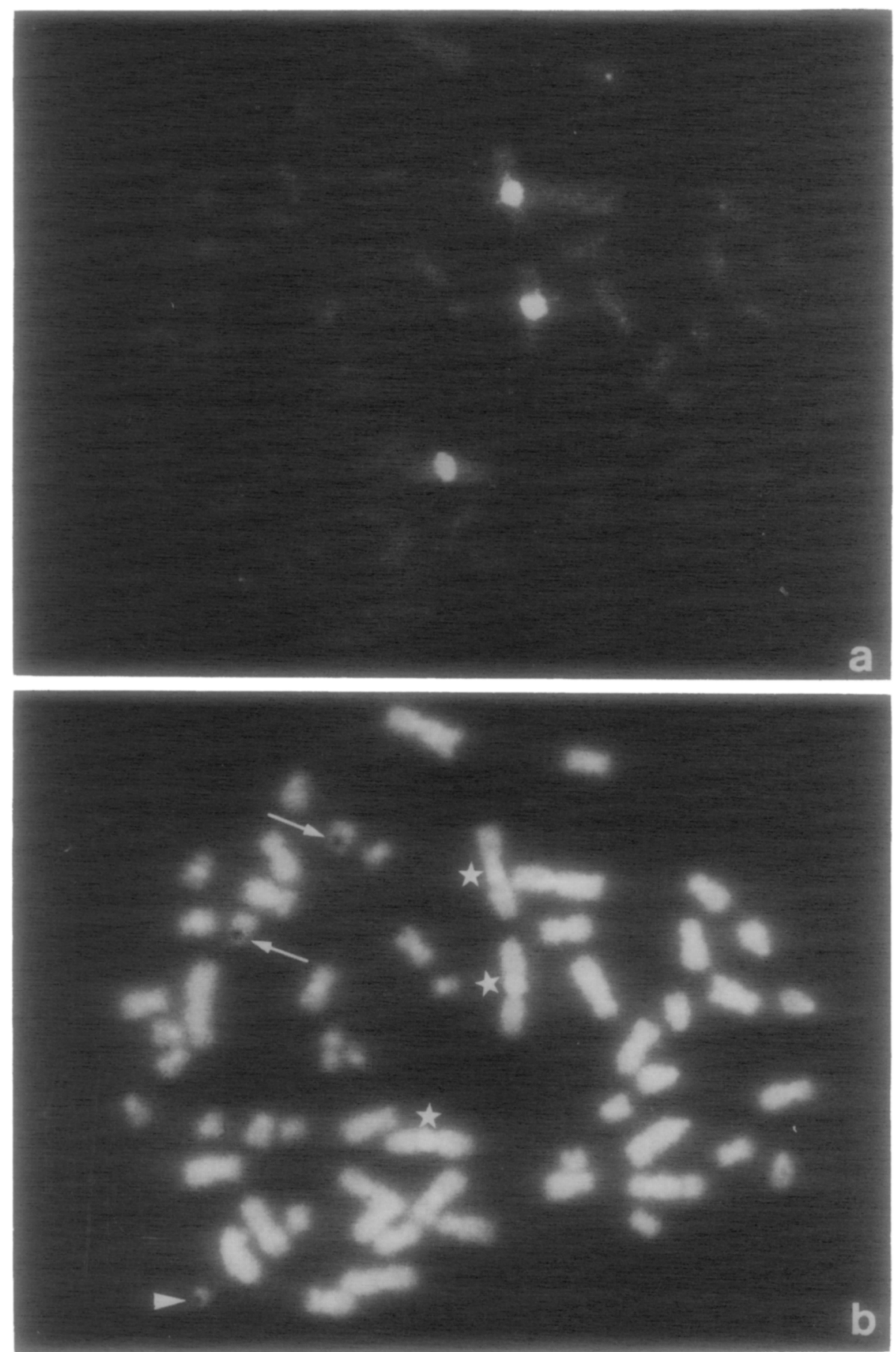

Fig. 7. TC 620 metaphase spread after double hybridization with (a) 1c (AAF/FITC) and (b) $18 \mathrm{c}$ (biotin/alkaline phosphatase). FITC fluorescence in $(a)$ shows three chromosomes 1 with distinctly fluorescent C-band regions. In $(b)$ these chromosomes are indicated by stars after DAPI staining. Arrows point to centromeric labeling of two apparently normal DAPI-fluorescent chromosomes 18 , and an additional structurally aberrant 18 (arrowhead). The aberrant 18 shows a partial deletion of the long arm and was consistantly observed in all metaphase spreads with three chromosomes $18 ; \times 2170$. 
TABLE 2

Glioma cells-Frequencies of $1 \mathrm{c}$ andlor $18 \mathrm{c}$ hybridization spots in interphase nuclei of thre human glioma cell lines

\begin{tabular}{|c|c|c|c|c|c|c|c|c|c|c|c|}
\hline \multirow{2}{*}{$\begin{array}{l}\text { Cell } \\
\text { type }\end{array}$} & \multirow[b]{2}{*}{ Experiments } & \multirow{2}{*}{$\begin{array}{l}\text { DNA } \\
\text { probe }\end{array}$} & \multirow{2}{*}{$\begin{array}{l}\text { Probe-label/ } \\
\text { detector }\end{array}$} & \multirow[b]{2}{*}{$n$} & \multicolumn{7}{|c|}{ Percentage of nuclei with spot number } \\
\hline & & & & & 0 & 1 & 2 & 3 & 4 & 5 & $\geqslant 6$ \\
\hline \multirow[t]{4}{*}{ TC 620} & II. $1-4$ & $1 \mathrm{c}$ & Biotin/TRITC (II.1) & 698 & 0.3 & 4.9 & 32.5 & 47.8 & 7.3 & 3.8 & 3.. \\
\hline & $($ mean $\pm S E M)$ & & $\mathrm{Hg} /$ FITC (II.2-4) & & \pm 0.3 & \pm 0.9 & \pm 4.2 & \pm 3.2 & \pm 1.2 & \pm 1.2 & \pm 0 . \\
\hline & II $3,4^{a}$ & $18 \mathrm{c}$ & Biotin/AP & 400 & 1.5 & 4.3 & 23.5 & 55.0 & 5.5 & 4.0 & 6. \\
\hline & & & & & \pm 1.5 & \pm 1.2 & \pm 9.5 & \pm 12.5 & \pm 0.5 & \pm 0.5 & \pm 0 . \\
\hline \multirow[t]{4}{*}{ TC 593} & II. $.5-7$ & $1 \mathrm{c}$ & Biotin/AP (II.5) & 324 & 0 & 0.6 & 12.1 & 19.1 & 61.3 & 3.2 & $3 . i$ \\
\hline & & & $\mathrm{Hg} /$ FITC (II.6,7) & & & \pm 0.6 & \pm 3.0 & \pm 1.1 & \pm 1.4 & \pm 1.9 & \pm 1 : \\
\hline & II $.6,7^{a}$ & $18 \mathrm{c}$ & Biotin/AP & 400 & 0.3 & 2.5 & 4.0 & 13.5 & 45.2 & 22.0 & $12 .:$ \\
\hline & & & & & \pm 0.3 & \pm 2.5 & \pm 3.0 & \pm 6.0 & \pm 5.2 & \pm 3.5 & \pm 3.1 \\
\hline \multirow[t]{2}{*}{ TC 526} & II. $8-10$ & $18 \mathrm{c}$ & Biotin/AP & 600 & 0 & 0.2 & 0.8 & 7.3 & 16.0 & 32.2 & $43 .:$ \\
\hline & & & & & & \pm 0.2 & \pm 0.6 & \pm 1.9 & \pm 3.5 & \pm 1.5 & \pm 7. \\
\hline
\end{tabular}

Note. $n$, number of nuclei; SEM, standard error of the mean. The peak fraction for each cell line is indicated in bold face type.

${ }^{a}$ II $, 3,4,6,7$, double hybridization experiments with mercurated $1 \mathrm{c}$ and biotinylated $18 \mathrm{c}$.

metaphase spreads of cell line TC 593 (Fig. 8a). Structural aberrations were obvious in both cell lines for chromosomes 18 . One chromosome 18 was reduced in size in TC 620 (Fig. 7 b), while in TC 593 a major hybridization site of 18c was consistently observed on the distal part of the long arm of a rearranged chromosome (Fig. $8 b$ ). Figures $9 c$ and 10 show two metaphase plates obtained from TC 526 after in situ hybridization with either $18 \mathrm{c}$ or 1c. Again numerical and structural aberrations were clearly apparent. In accord with the interphase nuclear hybridization pattern in TC 526 (Figs. $9 a, b$ ) there were marked differences in the intensity of $1 \mathrm{c}$ spots on different metaphase chromosomes (Fig. 10a). Notably, counts of the labeled chromosomes could be reliably made even in cases where spreading of the chromosomes was inadequate for a conventional cytogenetic analysis (Fig. 9c).

It was difficult to prepare adequate metaphase spreads of the neuroblastoma line TC 691 . However, we were able to reproducibly count chromosomes 1 and 18 in interphase nuclei of this near diploid tumor cell line (Table 3). These studies showed that chromosome 1 is trisomic in approximately $55 \%$ of the population. In contrast, double hybridization experiments showed that chromosome 18 signals were at diploid levels in these same nuclei. These results were confirmed in rare metaphase spreads (Figs. $11 a, b$ ). 1c spots in interphase nuclei suggested considerable variation in the decondensation of $1 \mathrm{q} 12$ regions in different nuclei and even within the same nucleus (Figs. $11 c, d$ ). It is unlikely that this variation was due to a pronounced polymorphism of this particular region as shown for TC 526 (Fig. 10a) since such a polymorphism was not apparent in some 20 metaphase spreads of TC 691. This phenotypically neuronal line also contained numerous double minutes (Fig. $11 \mathrm{c}$ ). 


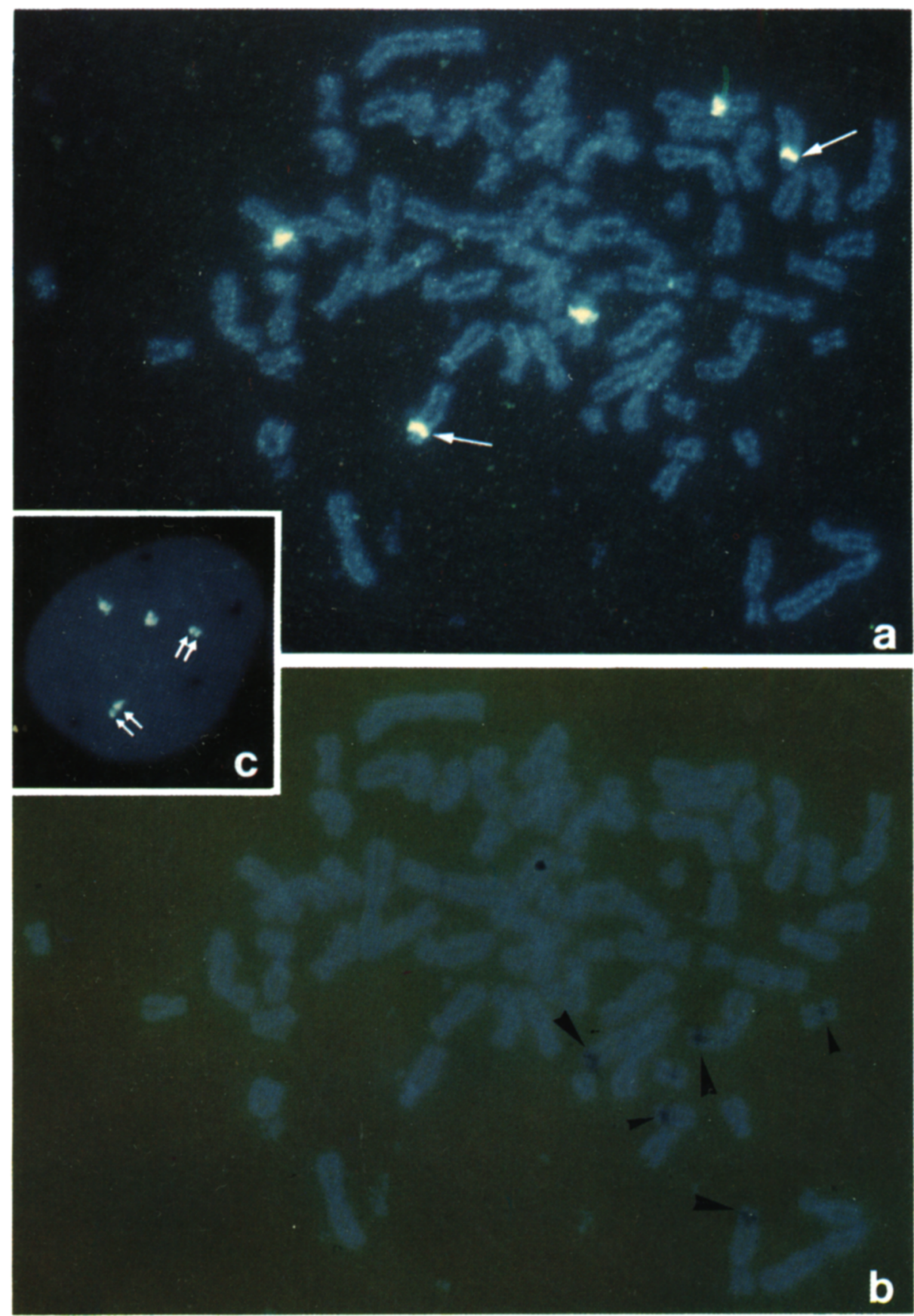

Fig. 8. Metaphase spread from human glioblastoma cell line TC 593 after double hybridization with (a) $1 \mathrm{c} \mathrm{(Hg/FITC)} \mathrm{and} \mathrm{(b)} 18 \mathrm{c}$ (biotin/alkaline phosphatase), counterstained with DAPI. FITC fluorescence in $(a)$ shows five structurally aberrant chromsomes 1 with strong lc labeling (double exposure FITC/DAPI), Arrows indicate two chromosomes 1 with deletions of the major part of the short arm. DAPI fluorescence combined with transmitted light is shown in $(b)$. The alkaline phosphatase reaction 
TABLE 3

euroblastoma cells-Frequencies of $1 c$ and $18 \mathrm{c}$ hybridization spots detected in interphas nuclei of the neuroblastoma cell line TC 691

\begin{tabular}{|c|c|c|c|c|c|c|c|c|}
\hline \multirow[b]{2}{*}{ Experiment } & \multirow{2}{*}{$\begin{array}{l}\text { DNA } \\
\text { probe }\end{array}$} & \multirow{2}{*}{$\begin{array}{l}\text { Probe-label/ } \\
\text { detector }\end{array}$} & \multirow[b]{2}{*}{$n$} & \multicolumn{5}{|c|}{ Percentage of nuclei with spot number } \\
\hline & & & & 0 & 1 & 2 & 3 & $\geqslant 4$ \\
\hline $1-5$ & $1 \mathrm{c}$ & $\mathrm{Hg} / \mathrm{FITC}$ & 815 & 0.6 & $\begin{array}{r}2.4 \\
+0.6\end{array}$ & $\begin{array}{r}40.8 \\
+2.1\end{array}$ & $\begin{array}{r}54.8 \\
+17\end{array}$ & $\begin{array}{r}1.4 \\
+0.5\end{array}$ \\
\hline$\left(\begin{array}{l}\text { (mean } \pm \text { SEM) } \\
.1,2^{a}\end{array}\right.$ & $18 \mathrm{c}$ & Biotin/AP & 400 & $\begin{array}{r} \pm 0.4 \\
1.3 \\
\pm 1.3\end{array}$ & $\begin{array}{r} \pm 0.6 \\
14.8 \\
\pm 2.3\end{array}$ & $\begin{array}{l} \pm 2.1 \\
79.5 \\
\pm 0.0\end{array}$ & $\begin{array}{r} \pm .1 \\
4.0 \\
\pm 3.0\end{array}$ & $\begin{array}{r} \pm 0.3 \\
0.5 \\
\pm 0.5\end{array}$ \\
\hline
\end{tabular}

Note. $n$, number of nuclei; SEM, standard error of the mean. The peak fraction is indicated in bold face type.

${ }^{a}$ III,1,2, double hybridization experiments with mercurated $1 \mathrm{c}$ and biotinylated $18 \mathrm{c}$.

\section{DISCUSSION}

We have shown that two repetitive DNA sequences confined to the constitutive heterochromatin of chromosomes 1 and 18 , can be reproducibly detected in interphase nuclei and metaphase spreads using several nonradioactive in situ hybridization procedures. The use of nonradioactive probes is advantageous for detecting nuclear signals due to high resolution and rapidity of signal detection [3, 6]. Double labeling procedures used here provided an important internal control for determinations of aneuploidy of specific chromosomes in tumor cells. Triple in situ hybridization experiments using biotinylated, mercurated, and AAFmodified DNA probes have recently become feasible (M. van der Ploeg, personal communication) and the introduction of additional labeling procedures may provide rapid simultaneous screening of even more than three specific chromosomal regions in the near future.

Cloned variants of the alphoid repeats such as $18 \mathrm{c}$ are not optimal as "chromosome-specific" probes since these sequences have some homology to repeated DNAs on essentially all human centromeres and are variants of a consensus sequence [3, 21-23, 31, 41]; 1c also has been reported to reveal minor hybridization sites on several other chromosomes [27]. In double hybridization experiments performed under a variety of less stringent hybridization conditions (not shown) we found, however, that $1 \mathrm{c}$ was still largely confined to 1q12, whereas $18 \mathrm{c}$ hybridized to the centromeric regions of most chromosomes [3]. The more extensive cross-hybridization of $18 \mathrm{c}$ probe is likely to account for the fact that in both normal diploid and glioma cell cultures nuclei with spot numbers above the peak fraction were generally somewhat more numerous for $18 \mathrm{c}$ as compared to $1 \mathrm{c}$

demonstrates six chromosomes decorated with the biotinylated $18 \mathrm{c}$ probe. While two chromosomes are clearly labeled at the centromeric region (small arrowheads) three other chromosomes are unexpectedly labeled at the distal part of the long arm (larger arrowheads). These abnormal patterns of 1 truncation and 18 rearrangements were observed in many spreads and are characteristic for TC 593. Insert (c) shows a typical nucleus from the same preparation with four clearly separated green fluorescent $\mathrm{lc}$ and four dark $18 \mathrm{c}$ spots. Note splitting of two 1c spots. Double exposure FITC/DAPI; $\times 1570$. 

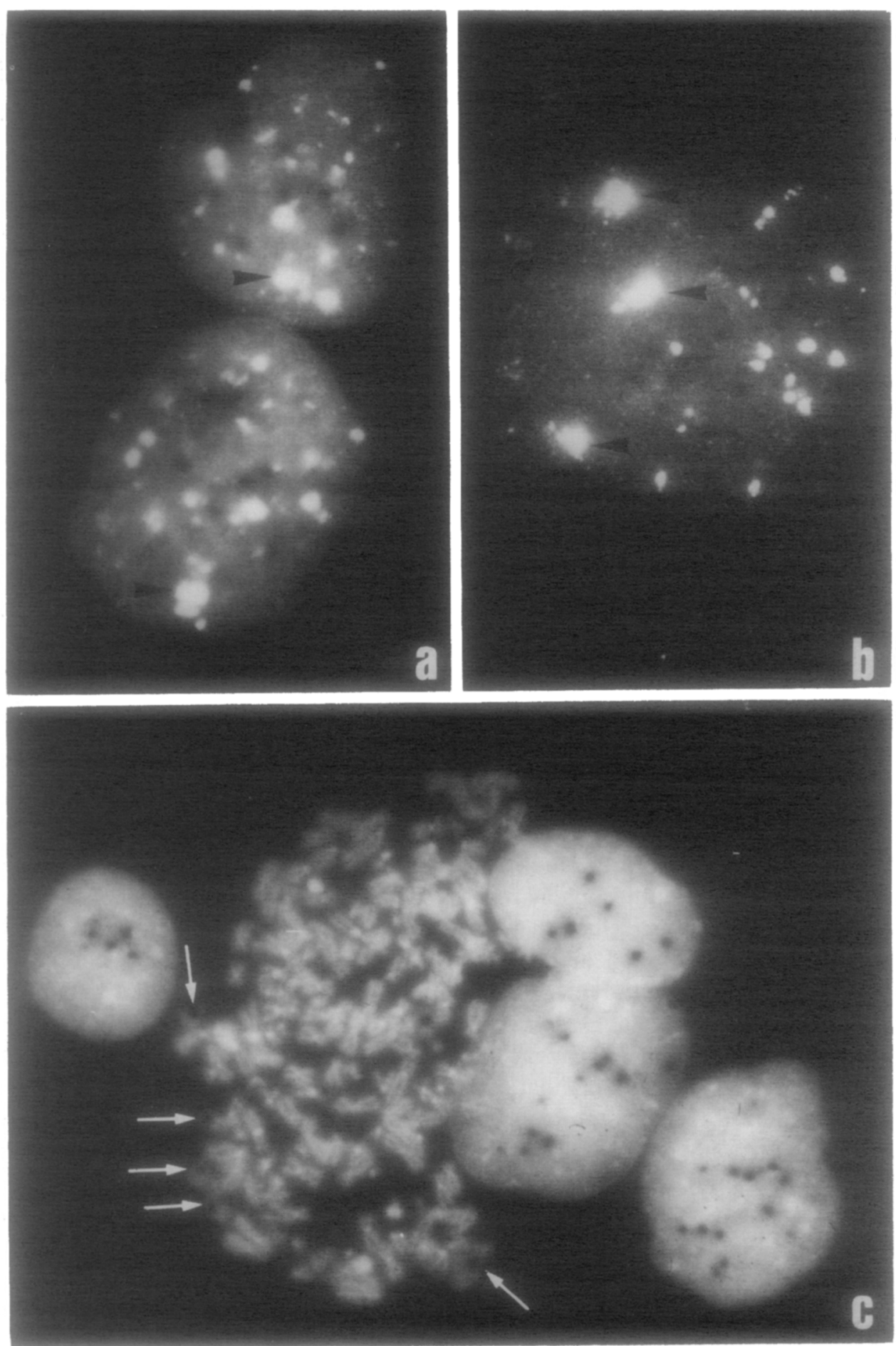

Fig. 9. Interphase nuclei $(a, b)$ and metaphase spread with adjacent interphase nuclei $(c)$ from human glioblastoma cell line TC 526 after hybridization with $1 \mathrm{c}(\mathrm{Hg} / \mathrm{FITC})(a, b)$ and $18 \mathrm{c}$ (biotin/alkaline phosphatase) (c) counterstained with DAPI; $(a)$ double exposure (FITC- plus DAPI-fluores- 
spots. Hybridization conditions have been defined for both probes that give reasonably specific chromosome signals in interphase nuclei; a clear peak of interphase counts matched the numbers obtained by analysis of metaphase spreads in all cell lines studied. Under these conditions the chromosome 1- or 18specific element can be readily distinguished by intensity of signal in the large majority of both metaphase and interphase cells. There is, however, a skewing of the curve for normal diploid nuclei from the predicted value of 2 to smaller values (Fig. $4 a$ ). This is largely preparation dependent and was independent of the choice of probe label, detection method utilized, or cell cycle stage (our unpublished data). While 0 -spot nuclei clearly indicated that probe penetration, hybridization, or detection failed in some individual nuclei, similar methodological limitations are also likely to account for the missing second spot in most 1-spot human diploid nuclei (see below). Conventional counts of metaphase spreads will also yield a slight underestimate of chromosome numbers due to different inherent technical limitations.

Estimates of aneuploidy based on previous overall chromosome counts [36] were entirely supported by the present in situ hybridization results. Furthermore, even in less than optimal metaphase preparations, abnormal chromosomes could clearly be delineated with these probes and in situ hybridization procedures. In complex aneuploid glioma lines we were rapidly able to pinpoint abnormal chromosomes in several instances; using conventional banding techniques the identification of translocated segments or abnormal truncated chromosomes in these cells was less obvious, especially in TC 526, due to multiple chromosome abnormalities. We have also shown that bizarre giant cells which represent a minor proportion of the population can be unequivocally delineated. It is not clear whether pairwise association of most $18 \mathrm{c}$ spots in the giant TC 620 nucleus shown in Fig. 6 indicates rare examples of homologous association of chromosome 18 centromeric regions (see below) or pronounced splitting of individual centromeric regions. Splitting of individual labeled $1 \mathrm{c}$ and $18 \mathrm{c}$ sites was occasionally observed in both normal diploid and tumor nuclci (Fig. $8 \mathrm{c}$ ).

Mitotic crossover events [42] can play an important role in the development of tumor cells [43]. The probability of such events may depend on the frequency with which homologous chromosomes are associated in a given cell population. In the normal diploid and tumor cell types studied here, there was clearly separation of homologous $1 \mathrm{c}$ and $18 \mathrm{c}$ spots in most interphase nuclei and the dispersion of these spots in double hybridization experiments is in accord with previous studies showing a wide distribution of centromeric regions in mouse and human neuroectodermal tumor nuclei $[39,44]$. As discussed above, 1-spot human diploid nuclei can be explained largely by technical reasons and are unlikely to

cence); (b) exposure of FITC-fluorescence only and ( $c$ ) of DAPI-fluorescence only. $(a, b)$ Nuclei show pronounced variability in size of the numerous $1 \mathrm{c}$ spots with some particularly large spots (arrowheads). (c) $18 \mathrm{c}$ spots in interphase nuclei and a metaphase spread which do not show such giant arrays. This micrograph also shows typical problems encountered in obtaining well-separated chromosomes from mitotic tumor cells with large chromosome numbers. However, chromosomes decorated with the $18 \mathrm{c}$ probe can be readily identified with these methods. Arrows point to some labeled chromosomes at the edge of the spread; $\times 1600$. 
216 Cremer et al.
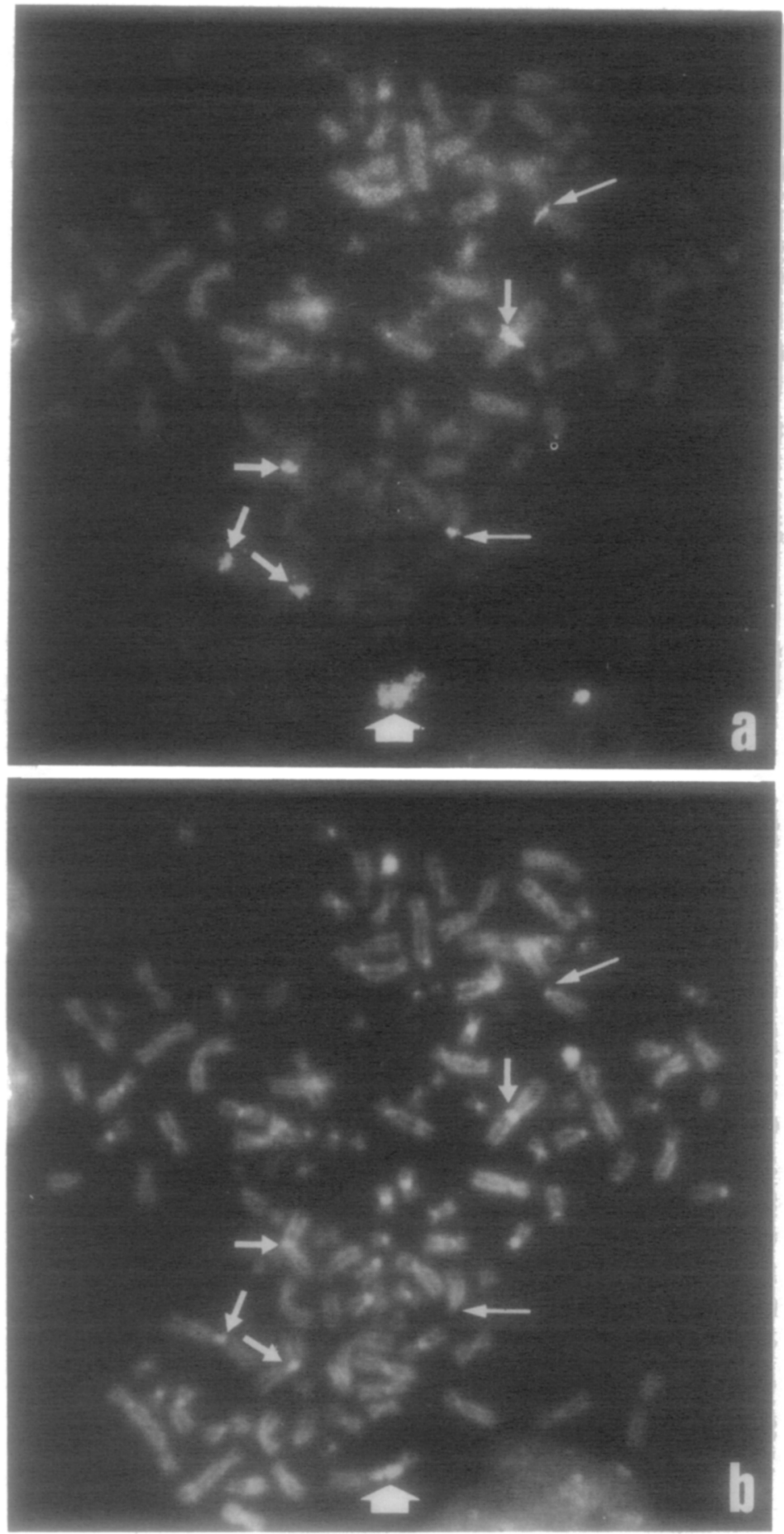

Fig. 10. Relatively simple metaphase plate from human glioma cell line TC 526 after hybridization with $1 \mathrm{c}(\mathrm{Hg} / \mathrm{FITC})$ and counterstaining with DAPI; $\times 1540$. (a) FITC fluorescence shows a strong polymorphism of 1c-labeled sites (arrows). A chromosome with particularly extended label, typically seen in many TC 526 metaphase spreads but not in the other cell lines, is indicated by a large arrow. 

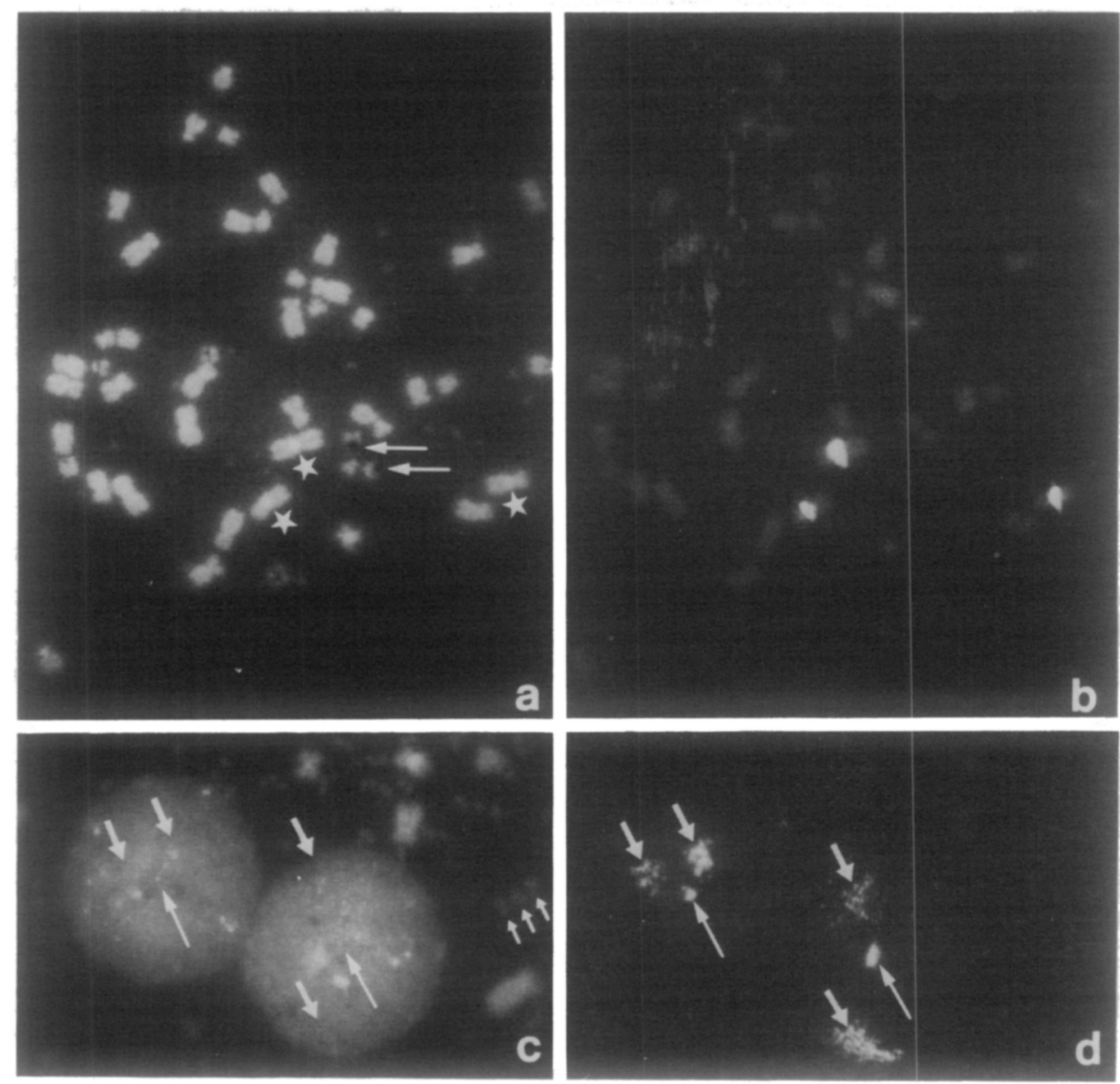

Fig. 11. $(a, b)$ Metaphase spread from human neuroblastoma cell line TC 691 after double hybridization with (a) 18c (biotin/alkaline phosphatase), counterstaining with DAPI, and $(b)$ ic $(\mathrm{Hg} / \mathrm{FlTC})$. Arrows in (a) show two chromosomes 18 decorated with the $18 \mathrm{c}$ probe; stars indicate three chromosomes 1. FITC fluorescence in $(b)$ shows strong 1c labeling over these chromsomes. (c, d) Two TC 691 interphase nuclei stained with DAPI $(c)$ and presenting three 1c spots in each nucleus (Hg/FITC) (d). The positions of two largely decondensed 1c labeled regions are indicated by corresponding thick arrows. Thin arrows indicate the position of a third compact ic spot. Small arrows in $(c)$ point to examples of numerous double minutes present in TC $691 ; \times 1400$.

include a considerable fraction with very close association of homologous spots. However, different species and even different cell types in the same tissue may largely differ with regard to the distribution of homologous chromosomes $[45,46$, L. Manuelidis, unpublished data]. Visualization of larger segments or even complete interphase chromosome domains (see below) in combination with threedimensional reconstruction should yield more complete data on the question of homologous chromosome associations in different human cell types.

Long thin arrows show two acrocentric chromosomes that are consistently labeled by the lc probe in many metaphase spreads of TC 526. Note that the variations in intensity and size of $1 \mathrm{c}$ label correlates with that seen in interphase nuclei (compare Figs. $9 a, b)$. (b) DAPI fluorescence of the same metaphase plate with corresponding arrows. 


\section{Cremer et al.}

A near diploid neuroblastoma line (TC 691) revealed a significant proportion of the population was trisomic for chromosome 1 but not for chromosome 18 . The significance of this disproportionate representation of chromosome 1 in neuroblastomas is currently unknown. However, structural rearrangements of chromosome 1 arc found nonrandomly in many tumors and are especially prevalent in neuroblastomas [47]. Of interest is the fact that this neuroblastoma line unlike many others, even after many serial passages, continues to develop many long neuritic processes without added nerve growth factor [36]. In many neuroblastomas as well as in normal developing adrenal medullary neurons [48] the extension of processes can be clicited by application of nerve growth factor. The gene for nerve growth factor is located on chromosome 1 [49] and it is tempting to speculate that TC 691 neuroblastoma cells trisomic for chromosome 1 may produce sufficient nerve growth factor to account for the prominent expression of neuritic processes in these cultures. Thus far, four oncogenes have been assigned to chromosome 1 and a dosage or allele effect of the $\mathrm{N}$-ras gene on one of the three chromosomes 1 could also contribute to the malignant phenotype of these cells $[47,50]$. Double minutes, suggestive of amplification, were also observed in TC 691 and are likely to contain N-myc amplified sequences found in many similar cases of neuroblastomas [51, 52]. The structure and expression of these pertinent genes in this cell line are currently under investigation.

Previous studies of nucleolus organizer regions containing ribosomal DNA regions have suggested that chromosomes may be more variably arranged in tumor cells than in normal cells [53]. In long-term cultures chromosome rearrangements and segregation effects may take place during the culturing process, or they may be a consequence of genetic instability which can underlie tumor progression and evolution. An inherent phenotypic instability of malignant glioma lines has been noted [54] and may reflect genetic changes within a tumor population. The present methods should allow one to monitor specific chromosomal changes in a small population of cells during the evolution of a tumor from a single cell clone. They should also be readily applicable to routinely embedded paraffin blocks $[55,56]$ for correlation of regional or rare population heterogeneity with prognosis in tumor specimen from patients (for review, see [2]). For example, low-grade astrocytomas that appear phenotypically "normal" may harbor rare genetic variants or subtle chromosomal changes that are a potential source of cells that contribute to tumor progression. Indeed "low-grade" gliomas frequently progress to highly malignant tumors.

Chromosomes 7 and 22 have been reported to be overrepresented and underrepresented, respectively, in malignant human gliomas [1, 2, 57] and probes for the specific delineation of these chromosomes in situ [22, 58] would be useful in studies of gliomas with different malignant propensities or at different stages of their evolution. Similarly, arrays of amplified sequences (devoid of common interspersed repeats) may also be useful for rapid screening of various gliomas; an amplified region containing the gli sequence has also recently been found in one malignant glioblastoma [59] and its general occurrence may be useful for prognostic studies using in situ hybridization. 
One disadvantage of the in situ approach is that even in the case of multihybridization protocols only a minor proportion of the karyotype can be simultaneously covered in a single experiment. A second disadvantage is that useful probe sets are currently limited; in addition to $1 \mathrm{c}$ and $18 \mathrm{c}$ used here, reliable probes for human chromosomes 9, 15, X, and Y are available $[15,20,21,25,30]$. However, specific probes sets exclusively limited to other chromosomes or chromosomal regions could become powerful tools of analysis where specific chromosomes are likely to be implicated. Clearly, single-copy sequences yield limited information about the normal representation of larger chromosome segments such as those involved in possible deletions, duplications, or translocations. Thus the isolation of sets of chromosome-unique sequences that define larger specific chromosome domains will be most useful in tumor studies using the methods described here. Construction of these specific probe sets is a major challenge for the further development of cytogenetics and will make the present double hybridization interphase approach increasingly powerful.

This work was supported by NIH Grant CA 15044. Thomas Cremer is the recipient of a Heisenberg fellowship from the Deutsche Forschungsgemeinschaft. We are grateful to Robert A. Baan, Howard J. Cooke, Peter Devilee and Peter Pearson for gifts of DNA-probes and antibodies, to Bill Fritch and Ed Zelazney for help with cell cultures and chromosome preparations, to Edda Schalt and Angelika Wiegenstein for help with photographic reproductions, to Mels van der Ploeg for a gift of AAFmodified $1 \mathrm{c}$ in an early stage of these experiments, to David Ward for helpful discussions, and to Uta Francke and Peter Lichter for comments on the manuscript.

\section{REFERENCES}

1. Bigner, H. B., Mark, J., Bullard, D. E., Mahaley, M. S., Jr., and Bigner, D. D. (1986) Cancer Genet. Cytogenet. 22, 121.

2. Shapiro, J. R. (1986) Semin. Oncol. 13, 4.

3. Cremer, T., Landegent, J., Hrückner, A., Scholl, H. P., Schardin, M., Hager, H. D., Devilee, P., Pearson, P., and van der Ploeg, M. (1986) Hum. Genet. 74, 346.

4. Langer-Safer, P. R., Levine, M., and Ward, D. C. (1982) Proc. Natl. Acad. Sci. USA 79, 4381.

5. Manuelidis, L., Langer-Safer, P. R., and Ward, D. C. (1982) J. Cell Biol. $95,619$.

6. Manuelidis, L. (1985) Focus 7, 4.

7. Landegent, J. E., Jansen in de Wal, N., Baan, R. A., Hoeijmakers, JHJ, and van der Ploeg, M. (1984) Exp. Cell Res. 153, 61.

8. Landegent, J. E., Jansen in de Wal, N., van Ommen, G. J. B., Baasd, F., de Vijlder, J. J. M., van Duijn, P., and van der Ploeg, M. (1985) Nature (London) 317, 175.

9. Hopman, A. H. N., Wiegart, J., and van Duijn, P. (1986) Iistochemistry 84, 169.

10. Hopman, A. H. N., Wiegart, J., and van Duijn, P. (1986) Histochemistry 84, 179.

11. Hopman, A. H. N., Wiegant, J., Raap, A. K., Landegent, J. E., van der Ploeg, M., and van Duijn, P. (1986) Histochemistry 85, 1.

12. Hopman, A. H. N., Wiegart, J., Tesser, G. I., and van Duijn, P. (1986) Nucleic Acids Res. 14, 6471 .

13. Hopman, A. H. N., Wiegant, J., and van Duijn, P. (1987) Exp. Cell Res. 169, 357.

14. Trask, B., van den Engh, G., Landegent, J., in de Wal, N. J., and van der Ploeg, M. (1985) Science 230, 1401.

15. Pinkel, D., Gray, J. W., Trask, B., van den Engh, G., Fuscoe, J., and van Dekken, H. (1986) Cold Spring Harbor Symp. Quant. Biol. 51, 151.

16. Schardin, M., Cremer, T., Hager, H. D., and Lang, M. (1985) Hum. Genet. 71, 281.

17. Durnam, M. D., Gelinas, R. E., and Myerson, D. (1985) Somatic Cell Mol. Genet. 11, 571.

18. Pinkel, D., Straume, T., and Gray, J. W. (1986) Proc. Natl. Acad. Sci USA 83, 2934.

19. Dudin, G., Cremer, T., Schardin, M., Hausmann, M., Bier, F., and Cremer, C. (1987) Hum. Genet. 76, 290.

20. Rappold, G. A., Cremer, T., Hager, H. D., Davies, K. E., Müller, C. R.. and Yang, T. (1984) Hum. Genet. 67, 317. 
21. Willard, H. F. (1985) Amer. J. Hum. Genet. 37, 524.

22. Lund Jorgensen, A., Bostock, C. J., and Leth Bak, A. (1986) Mol. Biol. 187, 185.

23. Devilee, P., Slagboom, P, Cornelisse, C. J., and Pearson, P. L. (1986) Nucleic Acids Res. 14, 2059.

24. Cooke, H. J., and Hindley, J. (1979) Nucleic Acids Res. 6, 3177.

25. Cooke, H. I., Schmidtke, J., and Gosden, J. R. (1982) Chromosoma 87, 491.

26. Müller, U., Donlon, T. A., Kunkel, S. M., Lalande, M., and Latt, S. A. (1987) Hum. Genet. 75, 109.

27. Gosden, J. R., Lawrie, S. S., and Cooke, H. J. (1981) Cytogenet. Cell Genet. 29, 32.

28. Joseph, A. M., Gosden, J. R., and Chandley, A. C. (1984) Hum. Genet. 66, 234.

29. Carine, K., Solus, J., Waltzer, E., Manch-Citron, J., Hamkalo, B. A., and Scheffler, J. E. (1986) Somatic Cell Mol. Genet. 12, 479.

30. Higgins, M. J., Wang, H., Shtromas, I., Haliotis, T., Roder, J. C., Holden, J. J. A., and White, B. N. (1985) Chromosoma 93, 77.

31. Devilee, P., Cremer, T., Slagboom, P., Bakker, E., Scholl, H. P., Hager, H. D., Stevenson, A. F. G., Cornelisse, C. I., and Pearson, P. I. (1986) Cytogenet. Cell Genet. 41, 193.

32. Yang, T. P., Hansen, S. K., Oishi, K. K., Ryder, O. A., and Hamkalo, B. A. (1982) Proc. Natl. Acad. Sci. USA 79, 6593.

33. Burns, J., Chan, VTW, Jonasson, J. A., Fleming, K. A., Taylor, S., and McGee, J. O. D. (1985) J. Clin. Pathol. 38, 1085.

34. Julien, C., Bazin, A., Guyot, B., Forestier, F., and Duffos, F. (1986) Lancet, $2,2447$.

35. Dale, R. M. K., Martin, F., Livingstone, D. C., and Ward, D. C. (1975) Biochemistry 14, 2447.

36. Manuelidis, L., and Manuelidis, E. E. (1979) Progress in Neuropathology (Zimmermann, H. M., Ed.), Vol. 4, p. 235. Raven Press, New York.

37. Manuelidis, E. E. (1969) Ann. N.Y. Acad. Sci. 159, 409.

38. Maniatis, T., Fritsch, E. F., and Sambrook, J. (1982) Molecular Cloning: A Laboratory Manual, Cold Spring Harbor Laboratory, Cold Spring Harbor, NY.

39. Manuelidis, L., and Ward, D. C. (1984) Chromosoma 91, 28.

40. Leary, J. J., Brigati, D. J., and Ward, D. C. (1983) Proc. Natl. Acad. Sci. USA 80, 4045.

41. Wu, J. C., and Manuelidis, L. (1980) J. Mol. Biol. 142, 363.

42. Therman, E., and Kuhn, E. M. (1981) Hum. Genet. 59, 93.

43. Cavenee, W. K., Dryja, T. P., Philipps, R. A., Benedict, W. F., Godbout, R., Gallie, B. L., Murphree, A. L., Strong, L. C., and White, R. L. (1983) Nature (London) 305, 779.

44. Manuelidis, L. (1984) Ann. N.Y. Acad. Sci. 450, 205.

45. Hadlaczky, G. Y., Went, M., and Ringertz, N. R. (1986) Exp. Cell Res. 167, 1.

46. Comings, D. E. (1980) Hum. Genet. 53, 131.

47. Atkin, N. B. (1986) Cancer Genet. Cytogenet. 21, 279.

48. Manuelidis, L., and Manuelidis, E. E. (1975) Brain Res. 96, 181.

49. Müncke, M., Lindgren, V., de Martinville, B., and Francke, U. (1984) Somatic Cell Mol Genet. $10,589$.

50. Hall, A., Marshall, C. J., Spurr, N. K., and Weiss, R. A. (1983) Nature (London) $303,396$.

51. Kohl, N. E., Kanda, N., Schreck, R. R., Bruns, G., Latt, S. A., Gilbert, F., and Alt, F. W. (1983) Cell 35, 359.

52. Schwab, M., Varmus, H. E., Bishop, J. M., Grzeschik, K.-H., Naylor, S. L. Sakaguchi, A. Y., Brodeur, G., and Trent, J. (1984) Nature (London) 308, 288.

53. Manuelidis, L. (1984) I. Neuropathol. Exp. Neurol. 43, 225.

54. Manuelidis, E. E. (1969) Ann. N.Y. Acad. Sci. 159, 409.

55. Brigati, D. J., Myerson, D., Leary, J. J., Spalholz, B., Travis, S. Z., Fong, C. K. Y., Hsiung, G. D., and Ward, D. C. (1983) Virology 126, 32.

56. Burns, J., Redfern, D. K. M., Esiri, M. M., and McGee, JO'D. (1986) J. Clin. Pathol. 39, 1066.

57. Henn, W., Blin, N., and Zang, K. D. (1986) Hum. Genet. 74, 104.

58. McDermid, H. E., Duncan, A. M. V., Higgins, M. J., Hamerton, J. L., Rector, E., Brasch, K. R., and White, B. N. (1986) Chromosoma 94, 228.

59. Kinzler, K. W., Bigner, S. H., Bigner, D. D., Trent, J. M., Law, M. L., O'Brien, S. J., Wong, A. J., and Vogelstein, B. (1987) Science 236, 70.

60. Siegel, S. (1956) Nonparametric Statistics for the Behavioral Sciences, McGraw-Hill, New York. 61. Manuelidis, L., and Manuelidis, E. E. (1979) Chromosoma 72, 257.

Received July 10, 1987

Revised version received September 18, 1987 